\title{
SOCIETAL VULNERABILITY TO IMPACTS OF EXTREME WEATHER EVENTS ON LAND TRANSPORT INFRASTRUCTURE
}

The paper is focused on understanding how failure of land transport infrastructure leads to societal vulnerability. It presents the multilevel approach to societal vulnerability measuring. The level of the societal vulnerability is expressed through the Vulnerability Index, which is calculated based on the vulnerability indicators. Identification and selection of those indicators are based on definition of vulnerability as a function of exposure, susceptibility to change and capacity to adapt to that change.

Keywords: societal vulnerability, transportation, critical infrastructure

\section{Introduction}

Transport infrastructure and services provided in transport are integral parts of everyday life of the population. Transport provides comprehensive service to the state territory and the functioning of the economy in the country [1]. It has a significant impact on socio-economic development and increases the standard of living and prosperity of society, increases the competitiveness of the country and its individual regions, contributes to elimination of unemployment and helps to reduce disparities between regions and states. It is also a key factor for the inflow of foreign investment and the development of tourism [2].

Enhancing safety and security in transport infrastructure is a key objective of the European Commission [3]. At present, one of the biggest threats facing the transport sector are extreme weather events and their impact on transport infrastructure [4], [5]. Over the past years, a variety of extreme weather events have threatened and disrupted transport infrastructure across many European countries and worldwide. The frequency of those events is expected to increase [6]. In this regard several projects, that addressed the sensitivity of transport system to extreme weather, were funded by the European Commission within the 7th Framework Programme for Research and Technological Development.The Project Risk Analysis of Infrastructure Networks in response to extreme weather (RAIN), solved within the call of FP7-SEC-2013-1, topic SEC-2013.2.1-2: Impact of extreme weather on critical infrastructure is one of them. It was focused on research of transport and energy/telecommunication infrastructures exposed to the impact of extreme weather hazards. The principal objective of the RAIN project was to provide an operational analysis framework to minimize the impact of major weather events on land based transportation and energy and telecommunications critical infrastructure in the EU. A holistic risk-based decision making framework was developed to establish the key components of those infrastructure networks and to assess their sensitivity to extreme weather events, as well as to facilitate identification of the impact of alternative mitigation measures [7].

University of Zilina, Faculty of Security Engineering participated in the RAIN project as a leader of the work package entitled "Land Transport Vulnerability". This work package was focused on the identification of critical land transport infrastructure, a review of failures as a result of extreme weather events, the current means of critical land transport infrastructure protection and development of an understanding how failure of this infrastructure leads to societal vulnerability.The aim of this paper is to present the scientific and technical results related to the work performed on assessing the Effects on Societal Vulnerability represented by the definition of Indicators of Societal Vulnerability and in the developed approach to measure vulnerability and specifically societal vulnerability due to the failure of critical land transport infrastructure elements.

\footnotetext{
* ${ }^{1}$ Maria Luskova, ${ }^{2}$ Michal Titko, ${ }^{3}$ Alan O'Connor

${ }^{1}$ Department of Technical Sciences and Informatics, Faculty of Security Engineering, University of Zilina, Slovakia

${ }^{2}$ Department of Crisis Management, Faculty of Security Engineering, University of Zilina, Slovakia

${ }^{3}$ Department of Civil, Structural \& Environmental Engineering, Trinity College Dublin, Ireland

E-mail: Maria.Luskova@fbi.uniza.sk
} 


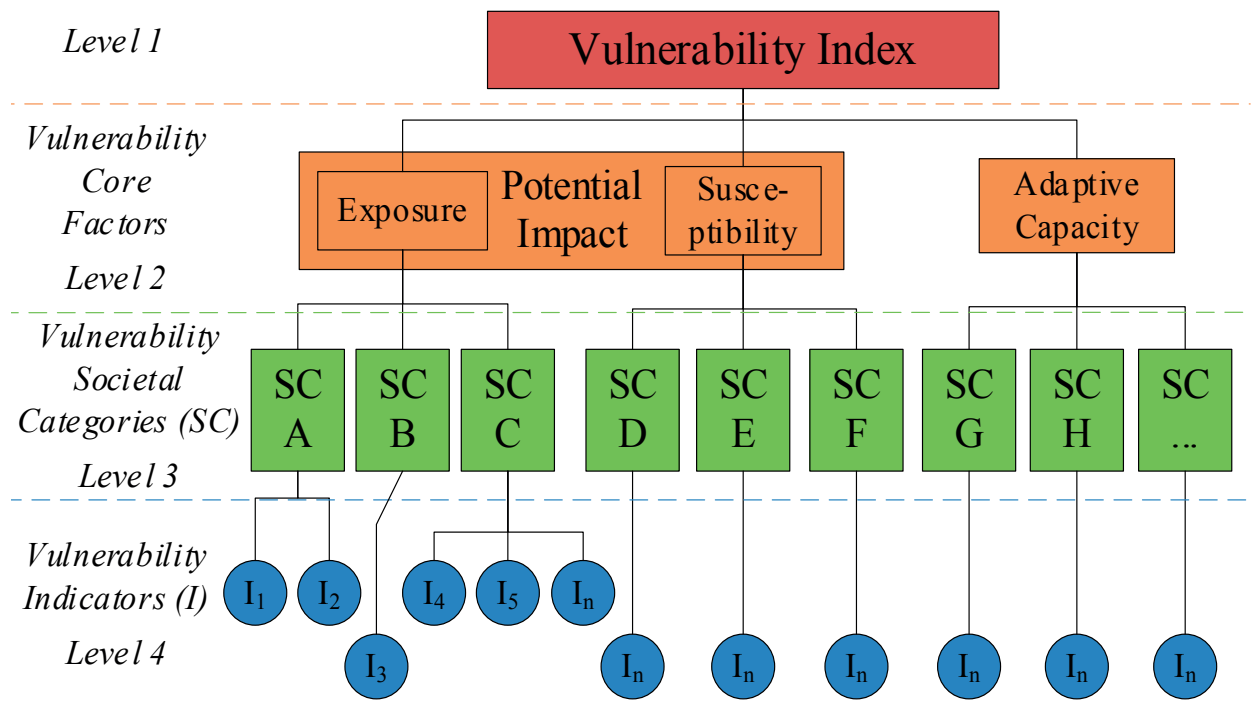

Figure 1 Multilevel Approach to the Vulnerability Index Identification

\section{Background}

The concept of vulnerability has emerged, discussed and continuously developed over almost past five decades, especially in the fields of geographic development and poverty research and hazard and disaster risk research. In the 1970s, research focused on disasters and crises associated with droughts in Africa, significantly contributed to development of social and societal vulnerability concept in geographic development and poverty research. Hazard and disaster risk research, associated with the disaster risk reduction, started in the 1980s. In the last two decades vulnerability has become also a key topic in the climate change science, as well [8].

The term "vulnerability" is used very loosely in dependence on an individual's background and the applied context [7], [8]. In the context of the transport network in connection with effects on society one can define societal vulnerability as an extent to which society is likely to be susceptible resulting from a lack of reliability of critical infrastructure [8], [9], [10], [11]). In this approach to development of understanding how a failure of the land-based critical infrastructure leads to societal vulnerability, that idea was followed. Moreover, for measuring the societal vulnerability, the structural approach was used, based on understanding of the vulnerability as a function of three core factors [8]:

- exposure to extreme weather events,

- susceptibility to change,

- capacity to adapt to that change.

Components of society, which can be in danger (Exposure), components, which are more sensitive to effects of extreme weather events (Susceptibility), as well as capacities (Adaptive Capacity), which assessed region is in disposal of, in order to manage the impacts of extreme weather events, were taken into consideration [12].

Therefore, it is proposed that the Societal Vulnerability should be expressed as a function of the mentioned core factors:

\section{Societal Vulnerability $=f$ (Exposure, Susceptibility, Adaptive} Capacity)

\section{Multilevel approach to societal vulnerability measuring}

The content of the individual core factors was questionable. This problem was solved within the RAIN by a structural, multilevel, big data approach (Figure 1). The approach was formulated by gradual splitting of Societal Vulnerability (represented by Vulnerability Index) into lower levels and, at the same time, the requirement for performing the vulnerability assessment by definition of relevant vulnerability indicators was fulfilled (Figure 2):

- Vulnerability Core Factors (3 factors).

- Vulnerability Societal Categories (9 categories).

- Vulnerability Indicators (31 indicators).

Within the proposed approach each Vulnerability Core Factor stands for one component of vulnerability which describes the actual state in a target region. According to assessment of the actual state, it is possible to subsequently determine the level of vulnerability in given region (exposure, susceptibility, adaptive capacity).

For each Vulnerability Core Factor it was necessary to define categories [13]; in this case Societal Categories. Societal 


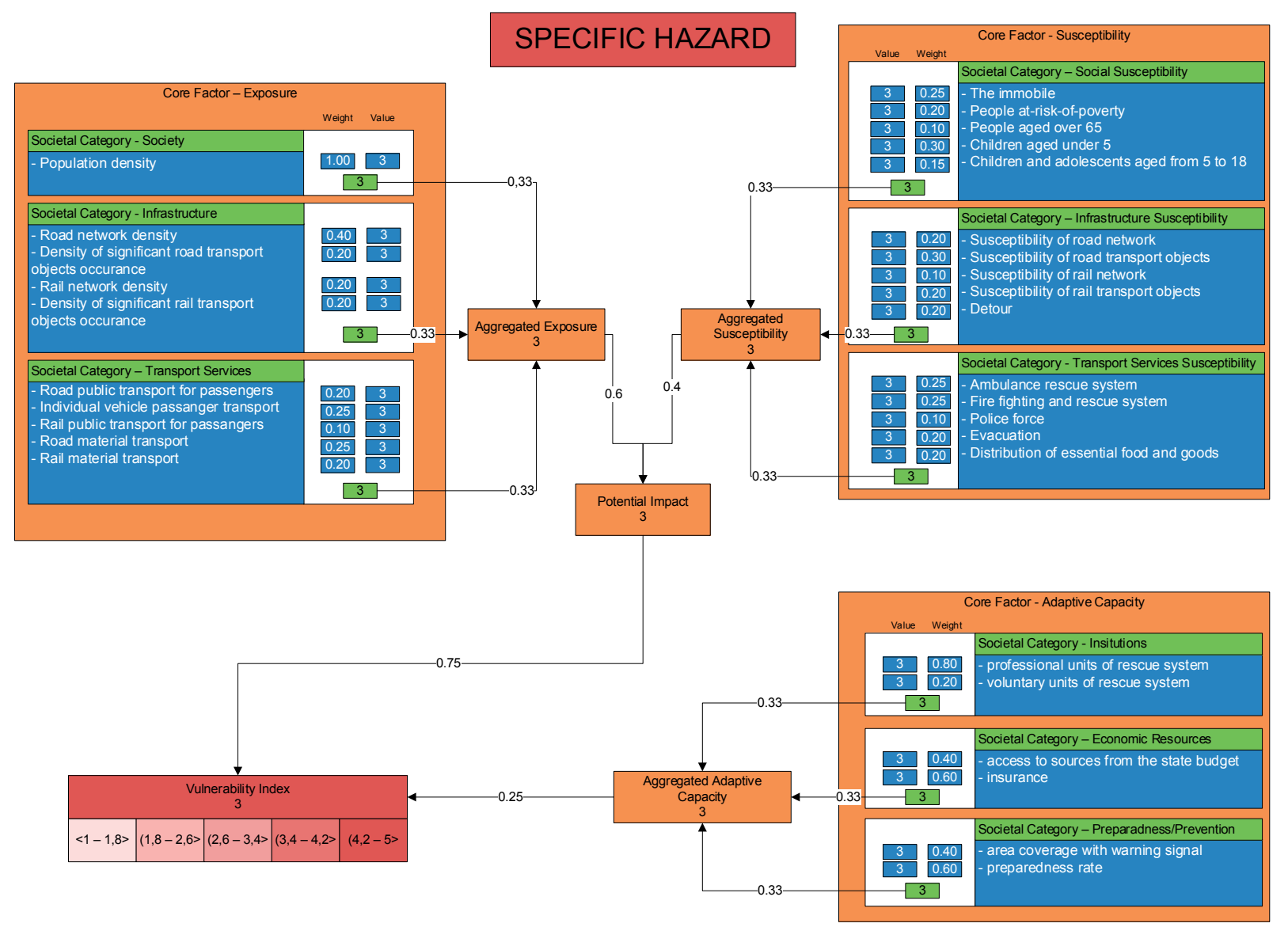

Figure 2 Multilevel approach to the Vulnerability Index calculation (example of given values)[4], [15], [16], [17], [18], [19], [20], [21]

Categories stand for those parts of society which form the main interest/centre of this research. They concern mainly transport critical infrastructure and society, hence, performing the functions of transport infrastructure operation for society.

Individual Societal Categories are formed by Vulnerability Indicators. Those Indicators describe concrete specific characteristics of each society, which are significant considering their vulnerability to extreme weather impacts.

As the selection of relevant indicators was the very important part of the research, the selection based on the following three sources was conducted:

- the indicators were selected based on the previous projects and investigations (ESPON CLIMATE [14]; ATEAM),

- related articles,

- indicators were also discussed with the subject matter experts in vulnerability task-related workshops (in the Netherlands, Spain, Slovakia). Experts were from the Dutch USAR-team (Urban Search and Rescue), Dutch police academy, United Kingdom Network Rail asset management, expert involved in $\mathrm{EC}$ and $\mathrm{UN}$-assessments and other researchers.

All selected indictors and societal categories within each core factor are shown in Figure 1.

\section{Vulnerability index calculation}

The Vulnerability Index (VI) is calculated by assessment of the mentioned levels (upwards). By assessment of the Vulnerability Indicators and integration of the Vulnerability Societal Categories and henceforth, within the Vulnerability Core Factors, one obtains the resulting value of VI. The Vulnerability Index represents unlimited value (values from 1 to 5 were proposed). Increasing values indicate increasing vulnerability. VI values have no strict interpretation, but if the given approach is applied on more sectors (areas) simultaneously, it is possible to compare them and it allows the identification of more vulnerable areas.

The Societal Vulnerability is so complicated to define in regard to society and transport that it was necessary to consider many factors and relations, which affect this vulnerability. It was found out that Vulnerability Indicators are so different that it was not possible to find a unifying unit to express the societal vulnerability (e.g. determination through money or other). Therefore, it was suggested to use the point's assessment for each Vulnerability Indicator. Each Indicator was given a value from 1 to 5 . As the relevance of indicators does not need to be the same, the indicators were given also weights of importance $\left(\mathrm{w}_{\mathrm{I}}\right)$. 
Table 1 Vulnerability Index values

\begin{tabular}{|c|c|}
\hline VI value & Description \\
\hline \multirow[t]{2}{*}{$\langle 1 ; 1.8\rangle$} & $\begin{array}{l}\text { The level of societal vulnerability is minimal. Indicators of societal vulnerability indicate that the examined region (area) is minimally } \\
\text { vulnerable in comparison to the average vulnerability in the country. It can be said that the examined region shows a negligible rate of } \\
\text { possible impacts caused by specific extreme weather event. Preparedness in terms of material resources and personnel capacities is at } \\
\text { a high level. }\end{array}$ \\
\hline & $\begin{array}{l}\text { In the long-term planning tasks aimed at maintaining the preparedness level of the society and monitoring the risk factors, changes that } \\
\text { could increase the vulnerability level should be included. }\end{array}$ \\
\hline \multirow[t]{2}{*}{$(1.8 ; 2.6>$} & $\begin{array}{l}\text { The level of societal vulnerability is low. Indicators of societal vulnerability indicate that the examined region (area) is less vulnerable } \\
\text { in comparison to the average vulnerability in the country. It can be said that the examined region shows an acceptable rate of possible } \\
\text { impacts caused by specific extreme weather event. Preparedness in terms of material resources and personnel capacities is at a sufficient } \\
\text { level. }\end{array}$ \\
\hline & $\begin{array}{l}\text { In the long-term planning tasks, aimed at reducing the risk factors that could endanger the examined region and maintaining a required } \\
\text { level of capacities for solving possible crisis, events should be included. }\end{array}$ \\
\hline \multirow[t]{2}{*}{$(2.6 ; 3.4>$} & $\begin{array}{l}\text { The level of societal vulnerability is medium. Indicators of societal vulnerability indicate that the vulnerability of examined region (area) is } \\
\text { comparable to the average vulnerability in the country. It can be said that the examined region shows a moderate rate of possible impacts } \\
\text { caused by specific extreme weather event. Preparedness in terms of material resources and personnel capacities is at a tolerable level, but } \\
\text { in the case of large-scale disasters could be insufficient. }\end{array}$ \\
\hline & $\begin{array}{l}\text { Within the crisis planning, in the medium-term aspect, tasks aimed at reducing the societal vulnerability level and increasing the level of } \\
\text { preparedness for coping with extreme weather, events should be included. }\end{array}$ \\
\hline \multirow[t]{2}{*}{$(3.4 ; 4.2>$} & $\begin{array}{l}\text { The level of societal vulnerability is high. The society contains several parts which are very sensitive to extreme weather event. Transport } \\
\text { network and society are poorly prepared to cope with the potential extreme event and very sensitive towards the impacts of that event } \\
\text { almost in every aspect. The transport network can be so disturbed that it is not possible to provide essential services for society. }\end{array}$ \\
\hline & $\begin{array}{l}\text { It is necessary to adopt measures to reduce the society susceptibility and to ensure the higher level of resources and personnel capacities } \\
\text { to cope with an extreme weather event. }\end{array}$ \\
\hline \multirow[t]{2}{*}{$(4.2 ; 5>$} & $\begin{array}{l}\text { The level of societal vulnerability is very high. The transport network and society contain many critical parts, which make them more } \\
\text { vulnerable. In addition, the transport network and society are minimally prepared to cope with respective crisis event and they are also } \\
\text { very sensitive towards the effects of the crisis event almost in every respect. Transport networks can be so disturbed that it is not possible } \\
\text { to provide essential services for society. }\end{array}$ \\
\hline & $\begin{array}{l}\text { It is necessary to make measures to reduce vulnerability as soon as possible because in the case of crisis event, extensive impacts on } \\
\text { society can occur. }\end{array}$ \\
\hline
\end{tabular}

To set the resulting value of Vulnerability Index, it is necessary to assess the weight of all the Core Factors, Societal Categories, as well as of all indicators $\left(\mathrm{w}_{\mathrm{I}}, \mathrm{w}_{\mathrm{SC}}, \mathrm{w}_{\mathrm{CF}}\right)$.

By summing the values of Vulnerability Indicators and considering indicator weights, values of Vulnerability Societal Category will be calculated according to relation:

$$
S C_{x}=\sum_{n=1}^{i} w_{l n} I_{n}
$$

where:

$\mathrm{SC}=$ Societal Category,

$\mathrm{x}=$ designation of Societal Categories,

$\mathrm{i}=$ number of indicators within Societal Category (from 1 to $\mathrm{n}_{\mathrm{x}}$ ),

$\mathrm{w}_{\mathrm{I}}=$ weight of Indicators,

$I_{n}=$ value of Indicators.

Similarly, values of Societal Categories were added to the value of the Core factor. As in the case of other indicators, even all the Societal Categories needed their weight $\left(\mathrm{w}_{\mathrm{SC}}\right)$ to be assessed. The aggregated value of the Core Factor is calculated according to relation:
$C F_{y}=\sum_{n=1}^{i} w_{S C_{n}} S C_{n}$

where:

$\mathrm{CF}=$ Core Factor,

$\mathrm{y}=$ designation of Core Factors,

$\mathrm{j}=$ number of Societal Categories within Core Factor (from 1 to $n_{\mathrm{y}}$ ), $\mathrm{w}_{\mathrm{sc}}=$ weight of Societal Category,

$\mathrm{SC}_{\mathrm{n}}=$ value of Societal Category.

The resulting value of the VI is obtained in a similar way as it was done in previous steps. The final calculation of the VI is preceded by an extra step, which lies in the calculation of Potential Impact (PI). Potential Impact represents possible level of impacts on society after considering all the aspects which can be in danger (Exposure) and after considering all the societal groups, which are more sensitive to extreme weather impacts (Susceptibility). The weights of Exposure and Susceptibility $\left(\mathrm{w}_{\mathrm{E}}\right.$, $\mathrm{w}_{\mathrm{S}}$ ) are counted as well. Sum of weight factors should be equal to 1. The Potential Impact is calculated according to relation:

$$
P I=w_{E} E+w_{S} S
$$




\section{kOMNIKCOCe}

where:

PI $=$ Potential Impact,

$\mathrm{E}=$ Exposure,

$\mathrm{S}=$ Susceptibility,

$\mathrm{w}_{\mathrm{E}}=$ weight of Exposure,

$\mathrm{w}_{\mathrm{S}}=$ weight of Susceptibility.

The resulting value for the VI is the sum of the PI weight value and the weight value of Adaptive Capacity:

$V I=w_{P I} P I+w_{A C} A C$

where:

$\mathrm{VI}=$ vulnerability index,

$\mathrm{AC}=$ Adaptive Capacity,

$\mathrm{w}_{\mathrm{PI}}=$ weight of $\mathrm{PI}$,

$\mathrm{w}_{\mathrm{AC}}=$ weight of Adaptive Capacity.

The proposed Vulnerability Index can obtain value from 1 to 5 . The higher VI value indicates the higher societal vulnerability. The index and related interpretations (Table 1) serve for evaluation of the current state in specific region, as well as for decision making purposes. In describing VI values, some recommendations for vulnerability reduction in terms of crisis planning, risk management and preparedness enhancing are provided. With increasing values of the VI, the time pressure for immediate reaction (vulnerability reduction), as well as the necessity of a higher level of resources and personnel capacities to cope with extreme weather events, is rising. If the given approach was applied to more sectors simultaneously, it is possible to compare them and it allows the identification of more vulnerable areas.

Authors [22], [23] argue that a system might be vulnerable to certain events, but be resilient to others; therefore it is important that while defining vulnerability one must consider hazardous events characteristic to the area under consideration. There could be significant differences between vulnerabilities of the same area to the same hazard with different intensity, e.g. windstorm with speed of $70 \mathrm{~km} /$ hour or $140 \mathrm{~km} /$ hour; flood with probability of occurrence 1 in 10 years, and flood with probability of occurrence 1 in 1000 years. Therefore, it is necessary to evaluate vulnerability for each threat or danger separately as it is illustrated in Figure 2.

Other methods for vulnerability analysis based on network modelling are suggested by authors of [24], [25].

\section{Conclusions}

Measuring and assessing vulnerability is a prerequisite for effective risk analysis and risk reduction, which was also confirmed within the RAIN project execution. If one is able to measure the societal vulnerability, one can adopt adequate measures for a target region and define disaster-risk management and disaster-relief priorities. Moreover, objective information to decision-makers (policy makers and public authorities - at all levels) and for all the relevant stakeholders (community as well) are provided. If the given approach is applied to more areas (regions) simultaneously, it is possible to compare them and it allows identification of the more vulnerable areas or communities. Exploring and understanding of societal vulnerability can addresses social, economic, security and environmental changes within the society, which can help to protect the most vulnerable parts of the society.

\section{Acknowledgements}

Publication of this paper was supported by the European Union within the FP7 project No. 608166 "Risk Analysis of Infrastructure Networks in response to extreme weather" and by VEGA grant No. 1/0240/15 "Process model of critical infrastructure safety and protection in the transport sector".

\section{References}

[1] Research Institute of Transport: Risk Analysis of the Transport Sector, Subsectors of Road Transport and Rail Transport (in Slovak). Zilina, 2014.

[2] Ministry of Transport and Construction of the Slovak Republic: Strategic Transport Development Plan of Slovakia by 2030 - Phase II. (in Slovak). Bratislava, 2016.

[3] European Commission: Transport Safety and Security [online]. 2016. Available: https://ec.europa.eu/jrc/en/research-topic/ transport-safety-and-security.

[4] SVENTEKOVA, E., DVORAK, Z., LEITNER, B.: Transport Critical Infrastructure in Slovak Republic.: Proceedings of the 8th International Multi-Conference on Complexity, Informatics and Cybernetics (IMCIC' 17), USA, 212-215, 2017.

[5] ZAGORECKI, A., RISTVEJ, J., KLUPA, K.: Analytics for Protecting Critical Infrastructure. Communications - Scientific Letters of the University of Zilina, 17(1), 111-115, 2015.

[6] O'CONNOR, A.: RAIN Project. Annex I, Description of Work, 2013.

[7] O'CONNOR, A.: RAIN Project. Final Report, Part A, 2017. 
[8] BIRKMANN, J.: Measuring Vulnerability to Natural Hazards: Towards Disaster Resilient Societies. United Nations University Press, Tokyo, Japan, 2013.

[9] TAYLOR, M. A. P., D’ESTE, G. M.: Concepts of Network Vulnerability and Applications to the Identification of Critical Elements of Transport Infrastructure. Proceedings of 26th Australasian Transport Research Forum, New Zeland, 2003.

[10] BERDICA, K.: An Introduction to Road Vulnerability: What Has Been Done, Is Done and Should Be Done. Transport Policy, 9(2), 117-127, 2002.

[11] JENEliUS, E., PETEMEN, T., MATTSSON, L. G.: Importance and Exposure in Road Network Vulnerability Analysis. Transportation Research Part A: Policy and Practice, 40(7), 537-560, 2006.

[12] FIELD C. B., BARROS V., STOCKER T. F., DAHE Q., DOKKEN D. J., ELBI K. L., MASTRANDREA M. D., MACH K. J.: Managing the Risks of Extreme Events and Disasters to Advance Climate Change Adaptation. Special Report of the Intergovernmental Panel on Climate Change, IPCC, Cambridge University, 2012.

[13] CUTTER, S., BURTON, C., EMRICH, C.: Disaster Resilience Indicators for Benchmarking Baseline Conditions. Journal of Homeland Security and Emergency Management, 7(1), 2010.

[14] GREIVING, S., FLEISCHHUAER, M., LINDNER, C., LUCKENKOTTER, J., PELTONEN, L., JUHOLA, S., VEHMAS, J., DAVOUDI, S., ACHINO, E., LANGELAND, O., LANGSET, B., MEDBY, P., SAURI, D., MARTIN-VIDE, J., OLCINA, J., PADILlA, E., VERA, F., HOLSTEN, A., BACKMAN, B., SCHMIDT-THOME, P., JARVA, J., TARVAINEN, T., KRUSE, S., SCHNELLER, K., CSETE, M., CHICOS, A., TESLIAR, J.: Espon Climate - Climate Change and Territorial Effects on Regions and Local Economies. Applied Research Project 2013/2014, Final Report, IRPUD, Dortmund, 2014.

[15] BURTON, G. CH., KHAZAI, B.: Social Vulnerability and Disaster Resilience in GEM [online]. Proceedings of the 15th World Conference on Earthquake Engineering: Global Earthquake Model Objectives and Activities, Portugal, 2012. Available: http:// www.globalquakemodel.org/media/cms_page_media/2012/11/14/SS1_GEM_3_SocialVulnerability.pdf.

[16] CARDONA, O. D., ORDAZ, M. G., MARULANDA, M. C., BARBAT, A. H.: Use of the Disaster Deficit Index in the Evaluation of the Fiscal Impact of Future Earthquakes [online]. Intersections, 6(2), article No. 1, 2009. Available: http://intersections.ro/ archive/2009/No02/Intersections_V06_No02_01.pdf.

[17] CUTTER, S. L., BORUFF, B. J., SHIRLEY, W. L.: Social Science Quarterly. Social Vulnerability to Environmental Hazards, 84(2), 242-261, 2003.

[18] NEDELIAKOVA, E., HUDAKOVA, M., STEFANCOVA. V.: Application of risk Management Methods in Transport Companies. Proceedings of 21th International Scientific Conference Transport Means 2017, Lithuania, 237-241, 2017.

[19] ISOARD, J., GROTHMANN, T., ZEBSICH, M.: Climate Change and Adaptation: Theory and Concepts. The Workshop: Climate Change Impacts and Adaptation in the European Alps: Focus Water, 2008.

[20] SCHNEIDERBAUER, S., PEDOTH, L., ZHANG, D., ZEBISCH, M.: Assessing Adaptive Capacity within Regional Climate Change Vulnerability Studies - An Alpine Example. Adaptation to Natural Hazards, 2011.

[21] SMIT, B., WANDEL, J.: Adaptation, Adaptive Capacity and Vulnerability. Global Environmental Change, 16(3), 282-292, 2006.

[22] DILlEY, M., BOUDREAU, T. E.: Coming to Terms with Vulnerability: a Critique of the Food Security Definition. Food Policy, 26, 229-247, 2001.

[23] WISNER, B., BLAIKIE, P., CANNON, T., DAVIS, I.: At risk: Natural Hazards, People's Vulnerability and Disasters, 2nd ed. Routledge, London, 2004.

[24] KHAKZAD, N., VAN GELDER, P.: Vulnerability of Industrial Plants to Flood-Induced Natechs: A Bayesian Network Approach. Reliability Engineering System Safety 169, 403-411, 2018. DOI:10.1016/j.ress.2017.09.016

[25] LI, H., HU, X., GUE, X., XU, Z., VAN GELDER, P. A.: New Quantitative Method for Studying the Vulnerability of Civil Aviation Network System to Spatially Localized Hazards. International Journal of Disaster Risk Science, 7(3), 2016. DOI: 10.1007/s13753016-0098-1 